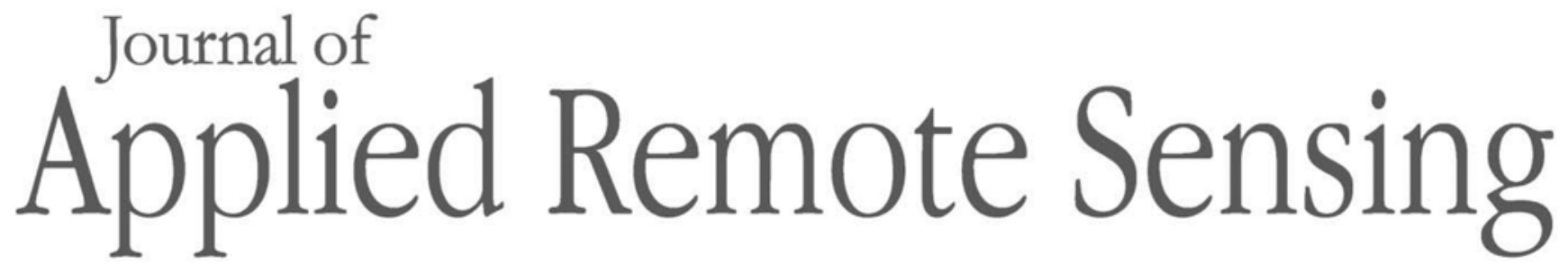

RemoteSensing.SPIEDigitalLibrary.org

\title{
Retrieval of absorption coefficients for a drinking water source using a green-red band quasianalytical algorithm
}

Liangliang Shi

Bangyi Tao

Zhihua Mao

Mingliang Liu

Yiwei Zhang 


\title{
Retrieval of absorption coefficients for a drinking water source using a green-red band quasianalytical algorithm
}

\author{
Liangliang Shi, ${ }^{\text {a,b }}$ Bangyi Tao, ${ }^{\mathrm{a}, *}$ Zhihua Mao, ${ }^{\text {a,b }}$ Mingliang Liu, ${ }^{\mathrm{c}}$ and \\ Yiwei Zhang ${ }^{\mathrm{d}, \mathrm{e}}$ \\ a Second Institute of Oceanography, State Oceanic Administration, State Key Laboratory of \\ Satellite Ocean Environment Dynamics, Hangzhou, China \\ ${ }^{b}$ Zhejiang University, Ocean College, Hangzhou, China \\ ${ }^{c}$ Hangzhou Institute of Environmental Science, Hangzhou, China \\ ${ }^{\mathrm{d}}$ Chinese Academy of Sciences, Shanghai Institute of Technical Physics, Shanghai, China \\ ${ }^{\mathrm{e}}$ University of Chinese Academy of Sciences, Beijing, China
}

\begin{abstract}
This study proposed a green-red band quasianalytical algorithm, QAA-GRI, and evaluates its performance using an in situ dataset from Lake Qiandaohu, a drinking water source, in China. First, by shifting the reference wavelength from 555 to $510 \mathrm{~nm}$, a green-red index (GRI) can be calculated from remote sensing reflectance at 510,560 , and $620 \mathrm{~nm}$, and the index was then used to retrieve the total absorption coefficients at the reference band, $a(510)$. Second, a semianalytical model based on $a(510)$ and the GRI was deduced to establish the QAA-GRI, replacing the empirical model in quasianalytical algorithm version 5 (QAA-v5). The QAA-GRI was applied to retrieve absorption coefficients from an in situ dataset of Lake Qiandaohu, and the QAA-GRI's performance was compared with that of QAA-v5 and another red-green QAAbased approach (QAA-RGR). The results demonstrate that, for this dataset, the QAA-GRI exhibited better performance $\left(R^{2}=0.81\right.$, mean absolute percentage error, MAPE $\left.=15.7 \%\right)$, which indicated a clear improvement in the accuracy of absorption coefficient retrieval, compared with QAA-v5 $\left(R^{2}=0.56\right.$, MAPE $\left.=21.2 \%\right)$ and QAA-RGR $\left(R^{2}=0.67\right.$, MAPE $\left.=22.6 \%\right)$. In addition, to illustrate the QAA-GRI's assumptions and its applicability, the QAA-GRI was also applied to an in situ dataset from Taihu Lake, a highly turbid and eutrophic water source. As predicted, when applied to Taihu Lake, the QAA-GRI did not perform as well as it did when applied to Lake Qiandaohu because of the former's extremely high turbidity, which can cause greater uncertainty with regard to backscattering coefficients. This study suggests that the QAA-GRI is better suited to the retrieval of absorption coefficients from drinking water resources. Our algorithm will also have potential applications to satellite data from the Medium Resolution Imaging Spectrometer or Ocean and Land Color Instrument. (c) The Authors. Published by SPIE under a Creative Commons Attribution 3.0 Unported License. Distribution or reproduction of this work in whole or in part requires full attribution of the original publication, including its DOI. [DOI: 10.1117/1.JRS.12.042802]
\end{abstract}

Keywords: absorption coefficient; green-red index; quasianalytical algorithm; remote sensing; drinking water sources.

Paper 180078SS received Jan. 23, 2018; accepted for publication May 11, 2018; published online Aug. 2, 2018.

\section{Introduction}

Absorption coefficients are important inherent optical properties (IOPs) of a water body. IOPs are directly linked to water constituents, including particulate matter and chromophoric dissolved organic matter (CDOM), and have been used to quantify the type of water, subsurface light intensity, solar heat flux with depth, pigment concentration, primary production of phytoplankton, and water color remote sensing. ${ }^{1-5}$ Therefore, understanding and retrieving IOPs of

*Address all correspondence to: Bangyi Tao, E-mail: taobangyi@sio.org.cn 
different water bodies are essential to determine appropriate management strategies for these important resources.

The absorption coefficient at a specific wavelength is indispensable for characterizing the marine bio-optical environment and establishing a remote sensing algorithm. Water color remote sensing is based on the relationships between remote sensing reflectance and IOPs, emphasizing total absorption and backscattering coefficients. ${ }^{6}$ Total absorption and backscattering coefficients determine the upwelling light field and can be retrieved using water-leaving reflectance determined from satellite observations. ${ }^{7}$ The variability of absorption coefficients in open ocean waters ("case 1 ") has been thoroughly documented over the last several decades. ${ }^{8-10}$ In recent years, methods for the accurate retrieval of total absorption in coastal or inland waters ("case 2") have also been under investigation, with proposed-models including empirical, ${ }^{11}$ spectral optimization, ${ }^{12}$ artificial neural network, ${ }^{13}$ linear matrix inversion, ${ }^{14}$ and semianalytical ${ }^{15}$ approaches.

Empirical models associate IOPs with remote sensing reflectance or the ratio of irradiance reflectance using simple or multiple regression methods. However, limitations occur in the application of these algorithms because of their optical complexity and the variation in different water bodies. To address the limitations and local dependency of an empirical model, Lee et al. ${ }^{4}$ developed a multiband quasianalytical algorithm (QAA) to derive absorption coefficients from remote sensing reflectance, and this algorithm has been widely applied to oceanic and coastal waters. The QAA includes two empirical models, three semianalytical models, and two analytical models; and it has been validated using in situ observations from various types of water bodies. The QAA has also been updated several times; its latest published version is QAA-v5. ${ }^{16}$ These updates primarily focus on the model for retrieving the absorption coefficients at $\sim 555 \mathrm{~nm}$ because in this range, total absorption is dominated by pure water, especially for case 1 waters. Several studies have reported that QAA-v5 cannot be directly applied to inland or coastal waters. ${ }^{17,18}$ Le et al. ${ }^{17}$ and Yang et al. ${ }^{18}$ further analyzed the factors that influence QAA-v5 and proposed their "local-specific" algorithms based on optimizing the reference wavelength position, in conjunction with local-specific optical properties, with the objective of retrieving absorption coefficients from highly turbid inland waters. In addition, Chen et al. ${ }^{19}$ proposed a QAA-based approach, QAA-RGR, that uses the ratio of remote sensing reflectance at the red $(645 \mathrm{~nm})$ and green $(555 \mathrm{~nm})$ bands to retrieve the absorption coefficient at the reference band $(555 \mathrm{~nm})$ from an in situ dataset collected for the East China Sea. The QAA-RGR exhibits a robust performance for the in situ data, and a better performance when applied in MODIS compared with QAA-v5 in the East China Sea.

However, both QAA-v5 and the other QAA-based algorithms have several weaknesses and uncertainties when applied to drinking water sources. The two empirical models involved in QAA-v5 were originally calibrated and validated with in situ datasets collected from oceanic and coastal areas, ${ }^{20,21}$ respectively, it is difficult to give an explanation of the empirical model from the mechanisms. The performance of these algorithms is of particular concern when applied to the unique optical environments of "local-specific" drinking waters. Unlike coastal and turbid inland waters, drinking waters usually have low concentrations of total suspended matter (TSM), and relatively high concentrations of CDOM compared with oceanic and some coastal waters. In addition, the optical properties of particulates in drinking waters are usually dominated by phytoplankton. Based on these facts, the empirical model used in both QAA-v5 and the QAA-based algorithms may fail when applied to drinking water resources.

Lake Qiandaohu is a small reservoir in China, and its IOPs change in a small range in response to seasonal and temporal variabilities. ${ }^{22}$ The lake's water quality is maintained at a high level, with a mean Secchi disk depth of $\sim 4.5 \mathrm{~m}$, and its dissolved oxygen concentration never falls below $2 \mathrm{mg} / \mathrm{L}^{23}$ These characteristics differ significantly from those of Taihu Lake, the water quality of which suffers dramatic change in both IOPs and trophic levels. ${ }^{24,25}$ Although several QAA-based approaches have been successfully applied to highly turbid waters, such as Taihu Lake, those algorithms must be adjusted to consider the differences between the bio-optical properties of the two lakes, and the QAA's performance must be further validated for drinking water resources, such as Lake Qiandaohu.

This study aims to remedy this deficiency with an improved algorithm for drinking water sources, in which a semianalytical model based on a green-red index is established to estimate 
the absorption coefficients at the reference band of $510 \mathrm{~nm}$. This model, which expresses more physical properties than previous models, offers more potential for deriving absorption coefficients than the original empirical model used in the QAA. Our results indicate that the proposed approach provides an effective alternative for investigating the IOPs of drinking water sources, as well as theoretical insight into other water bodies with similar optical type.

\section{Materials and Methods}

\subsection{Study Area}

Lake Qiandaohu $\left(118^{\circ} 34^{\prime}\right.$ to $119^{\circ} 15^{\prime} \mathrm{E}, 29^{\circ} 22^{\prime}$ to $\left.29^{\circ} 50^{\prime} \mathrm{N}\right)$, meaning Thousand Island Lake in Chinese, is a freshwater lake in Zhejiang Province, China, and is part of Xin' an Jiang Reservoir. The lake also attracts tourists, who come for its clear water and numerous islands [Fig. 1(a)]. The water quality of Lake Qiandaohu is described as oligotrophic, although it has been trending toward mesotrophic. ${ }^{23}$ The mean total phosphorus, total nitrogen, and Secchi depth of Lake Qiandaohu are $0.025 \mathrm{mg} / \mathrm{L}, 1.042 \mathrm{mg} / \mathrm{L}$, and $4.7 \mathrm{~m}$, respectively, and the magnitude of absorption by particulates and CDOM is low (as detailed in Table 1). The lake has a surface water area of $580 \mathrm{~km}^{2}$ and a mean depth of $37 \mathrm{~m}$ at its normal water level. It is a long and narrow reservoir with more than 80 bays. The reservoir was constructed in 1959 and has served a variety of purposes, including as the drinking water supply for more than 9.0 million people in Hangzhou city. In comparison, Taihu Lake $\left(118^{\circ} 34^{\prime}\right.$ to $119^{\circ} 15^{\prime} \mathrm{E}$ and $29^{\circ} 22^{\prime}$ to $29^{\circ} 50^{\prime} \mathrm{N}$ ) is the third largest lake in China [Fig. 1(b)]. Its water surface area and mean water depth are $2340 \mathrm{~km}^{2}$ and $1.8 \mathrm{~m}$, respectively. Lake Taihu's eutrophication, high levels of TSM, and algal bloom have caused significant concern and motivated several studies; these factors also cause the IOPs of Taihu Lake to be very different from those of Lake Qiandaohu.

\subsection{Field Sampling and Laboratory Measurements}

Field samples were collected from Lake Qiandaohu during nine campaigns from June 2015 to June 2016 (June 1-3, July 7-10, August 4-7, October 9-12, November 3-7, and December 1-4, 2015; March 1-5, May 3-7, and June 1-3, 2016). The sampling dates and location are shown in Fig. 1(a). A total of 144 water samples were collected, among which 63 samples [at lettered stations in Fig. 1(a)] were collected for optical analysis. Another field campaign was conducted at Taihu Lake on May 15-26, 2015, from 38 sampling stations, the distribution of which can be seen in Fig. 1(b).

Water samples were collected from depths above $0.5 \mathrm{~m}$, and then filtered on $0.45-\mu \mathrm{m}$ Whatman glass fiber GF/F filters. The filtered samples were stored in a dark container with liquid nitrogen and taken to the laboratory for chlorophyll- $a$ (Chl- $a$ ) concentration analysis within $6 \mathrm{~h}$. The Chl- $a$ was extracted from the filtered samples in hot $\left(80^{\circ} \mathrm{C}\right) 90 \%$ ethanol, the extract was cleared by centrifugation, and the Chl-a concentration was then determined fluorometrically using a Turner fluoroprobe with two replicated measurements following the EPA Method. ${ }^{26}$

\subsection{Absorption Measurements}

Several studies ${ }^{27,28}$ have indicated that the total spectral absorption coefficient $[a(\lambda)]$ is the sum of the spectral absorption coefficients of pure water $\left[a_{w}(\lambda)\right]$, particles $\left[a_{p}(\lambda)\right]$ (including phytoplankton $\left[a_{p h}(\lambda)\right]$, nonalgal particles (NAP) $\left[a_{\mathrm{NAP}}(\lambda)\right]$, and CDOM $\left[a_{\mathrm{CDOM}}(\lambda)\right]$

$$
a(\lambda)=a_{w}(\lambda)+a_{p h}(\lambda)+a_{\mathrm{NAP}}(\lambda)+a_{\mathrm{CDOM}}(\lambda),
$$

where $a_{w}(\lambda)$ is rather constant, as reported by Pope and Fry. ${ }^{29}$ The methods for laboratory measurements of $a_{p}(\lambda), a_{p h}(\lambda), a_{\mathrm{NAP}}(\lambda)$, and $a_{\mathrm{CDOM}}(\lambda)$ are described in detail by Babin et al. ${ }^{30}$ and in our previous study. ${ }^{22}$

For this study, water samples were processed onboard the ship immediately after collection. CDOM samples were first filtered through a $47-\mathrm{mm}$ diameter Whatman GF/F filter with a pore 




Fig. 1 (a) Location of Lake Qiandaohu, and distribution of sampling sites during nine cruises in Lake Qiandaohu; water quality parameters were collected at all stations, and optical sampling, including absorption and remote sensing reflectance measurements, was conducted at the 12 lettered stations. (b) Location of Taihu Lake, and distribution of sampling sites in Taihu Lake on May 2015.

size of $0.7 \mu \mathrm{m}$, and then refiltered through 47-mm diameter millipore polycarbonate filters with pore sizes of $0.22 \mu \mathrm{m}$, before being stored in the darkness in a refrigerator. For the particle samples, water volumes of 50 to $500 \mathrm{~mL}$ were filtered through 25 -mm-diameter Whatman $\mathrm{GF} / \mathrm{F}$ filters and then kept in a container with liquid nitrogen. These treated samples were 
Table 1 Water constituent concentrations and IOPs of the samples collected from Lake Qiandaohu during all nine cruises.

\begin{tabular}{lccccccc}
\hline \hline & $\begin{array}{c}\text { Chl-a } \\
(\mu \mathrm{g} / \mathrm{L})\end{array}$ & $\begin{array}{c}\text { Turbidity } \\
(\mathrm{NTU})\end{array}$ & $\begin{array}{c}R_{r s}(550) \\
\left(\mathrm{sr}^{-1}\right)\end{array}$ & $\begin{array}{c}a_{\mathrm{P}}(440) \\
\left(\mathrm{m}^{-1}\right)\end{array}$ & $\begin{array}{c}a_{\mathrm{NAP}}(440) \\
\left(\mathrm{m}^{-1}\right)\end{array}$ & $\begin{array}{c}a_{\mathrm{CDOM}}(440) \\
\left(\mathrm{m}^{-1}\right)\end{array}$ & $\begin{array}{c}a_{p h}(675) \\
\left(\mathrm{m}^{-1}\right)\end{array}$ \\
\hline $\operatorname{Max}$ & 30.35 & 20.50 & 0.013 & 0.548 & 0.114 & 0.435 & 0.242 \\
$\operatorname{Min}$ & 0.37 & 0.35 & 0.003 & 0.045 & 0.026 & 0.134 & 0.008 \\
Avg. & 5.62 & 2.27 & 0.006 & 0.164 & 0.055 & 0.265 & 0.053 \\
Med. & 4.56 & 2.92 & 0.006 & 0.127 & 0.049 & 0.253 & 0.037 \\
Sd. & 5.28 & 2.93 & 0.002 & 0.108 & 0.020 & 0.085 & 0.046 \\
\hline \hline
\end{tabular}

Note: Avg., average; Med., median; Sd., standard deviation.

later taken back to the laboratory for analysis of optical variables. The absorption coefficients of CDOM, $a_{\mathrm{CDOM}}(\lambda)$, were measured over 250 to $860 \mathrm{~nm}$ in 1-nm increments using a Perkin Elmer (PE) lambda-35 spectrophotometer. Then, $a_{p}(\lambda), a_{p h}(\lambda)$, and $a_{\mathrm{NAP}}(\lambda)$ were determined according to the quantitative filter technique, ${ }^{31}$ calculated from their absorbances measured over 300 to $800 \mathrm{~nm}$ in 1-nm increments using a PE lambda-950 spectrophotometer.

\subsection{Remote Sensing Reflectance Measurements}

Synchronous with the water sampling, remote sensing reflectance above the water surface was measured using an ASD field spectrometer (Analytical Spectral Devices, Inc., Boulder Colorado), with a spectral range of 350 to $1050 \mathrm{~nm}$ and a spectral resolution of $1.58 \mathrm{~nm}$. For a detailed discussion of in situ spectral measurements above water, see Fargion and Mueller. ${ }^{32}$ Remote sensing reflectance measurements for Lake Qiandaohu were collected only at those stations identified by letters in Fig. 1(a). All measurements of reflectance were performed between 9:30 and 15:00 local time. The radiance of water, sky, and a standard Spectralon reflectance plaque was measured 20 times for each target. The radiance spectra from 20 scans of each target were averaged, and then the remote sensing reflectance, $R_{r s}(\lambda)$, was calculated from the average according to the following equation:

$$
R_{r s}(\lambda)=\frac{L_{w}(\lambda)}{E_{d}\left(0^{+}, \lambda\right)}=\frac{L_{s w}(\lambda)-r L_{\mathrm{sky}}(\lambda)}{\pi L_{p}(\lambda) / \rho_{p}},
$$

where $L_{w}(\lambda)$ is the water-leaving radiance, $E_{d}\left(0^{+}, \lambda\right)$ is the downward irradiance, $L_{s w}(\lambda)$ is the total radiance from the water surface, $L_{\text {sky }}(\lambda)$ is the diffused radiance from the sky, $L_{p}(\lambda)$ represents the radiance of the reference panel, $\rho_{p}$ represents the reflectance of the Spectralon plaque with Lambertian characteristics, and $r$ refers to sea surface skylight reflectance, which is not spectrally constant and is determined by the surface wind speed and the spectral distribution of skylight. Therefore, for this study, an average value of 0.026 in cloudy calm weather, and a value of 0.024 in sunny calm weather, was used according to Cui et al. ${ }^{33}$ Prior research has indicated that bottom reflectance affects the water surface reflectance in shallow waters. ${ }^{34}$ However, in this paper, when calculating $R_{r s}(\lambda)$, this effect was considered negligible because Lake Qiandaohu is an optically deep lake, where light cannot penetrate to the bottom.

\subsection{Algorithm Development}

In QAA-v5, as reported by Lee et al., ${ }^{16}$ the wavelength of $555 \mathrm{~nm}$ is used as the reference wavelength. However, Lee et al. ${ }^{4}$ indicated that the reference wavelength should be shifted to a longer wavelength for high-absorption waters. Le et al. ${ }^{17}$ proposed a QAA-710 algorithm, in which $710 \mathrm{~nm}$ was used as the reference band for highly turbid waters. Chen et al ${ }^{19}$ modeled the empirical relationship between $a(555)$ and the ratio of $R_{r s}(640)$ to $R_{r s}(555)$, substituting the empirical model (step 2) in QAA_v5. Here, to adapt the general structure of the QAA for application to 
drinking water sources, we propose replacing the original empirical model with a semianalytical model of the relationship between $a(510)$ and a green-red index (GRI). In the proposed model, $510 \mathrm{~nm}$ is chosen as the reference band, and the derivation of $a(510)$ is presented step-by-step based on several reasonable assumptions.

\subsubsection{QAA-GRI algorithm}

Although spectral remote sensing reflectance, $R_{r s}(\lambda)$, can be estimated from the ratio of waterleaving radiance, $L_{w}(\lambda)$ to downward irradiance, $E_{d}\left(0^{+}, \lambda\right)$, as in Eq. (2), Gordon et al. ${ }^{35}$ and Carder et al. ${ }^{36}$ have shown that in a homogeneous water body, $R_{r s}(\lambda)$ can also be defined in terms of IOPs, namely total absorption $[a(\lambda)]$ and backscattering $\left[b_{b}(\lambda)\right]$ coefficients as follows:

$$
R_{r s}(\lambda) \propto \frac{f}{Q} \frac{b_{b}(\lambda)}{a(\lambda)+b_{b}(\lambda)},
$$

where $f$ / $Q$ ratio is a coefficient dependent on the geometry of the light field from the water body, spectrally related to the sun's zenith angle and the volume scattering function. ${ }^{37}$ The variation in $f / Q$ is not significant according to Loisel and Morel; ${ }^{38}$ its value changes at maximum by $\sim 20 \%$. For proper viewing angles in the remote sensing domain and with a solar zenith angle $<60 \mathrm{deg}$, the variation of $f / Q$ is quite small (below $10 \%$ ). Therefore, as a first approximation, the $f / Q$ ratio is assumed to be spectrally invariant in the band range from 500 to $650 \mathrm{~nm}$. To obtain a function directly related to $a_{p c}(\lambda)$, we adjust Eq. (3) as follows:

$$
R_{r s}(\lambda) \propto \frac{f}{Q} \frac{b_{b}(\lambda)}{a_{w}(\lambda)+a_{p c}(\lambda)+b_{b}(\lambda)},
$$

where $a(\lambda)=a_{w}(\lambda)+a_{p c}(\lambda)$, and $a_{p c}(\lambda)$ can be expressed as $a_{p c}(\lambda)=a_{p}(\lambda)+a_{\mathrm{CDOM}}(\lambda)$. We also assume that the difference in $a_{p c}(\lambda)$ between the 560- and 620-nm bands is small. Thus, as a second approximation, the following assumption can be made for each $a_{p c}(\lambda)$ spectrum

$$
a_{p c}(560)=a_{p c}(620) \text {. }
$$

In addition, the spectral dependence of $b_{b}(\lambda)$ is considered to be weak, and its variation between 500 and $650 \mathrm{~nm}$ is supposed to be small, especially in drinking water sources. ${ }^{39,40}$ From this point onward, $b_{b}(\lambda)$ is assumed to be equal in the three bands of 510, 560, and $620 \mathrm{~nm}$ for drinking water sources. Based on this assumption, we can obtain the following relationship between the three bands:

$$
b_{b}(510)=b_{b}(560)=b_{b}(620) \text {. }
$$

To isolate $b_{b}(560)$ or $b_{b}(620)$ from Eq. (4) by minimizing the effects of $b_{b}$, we first remove $b_{b}$ from the denominator of Eq. (4) using the other two values of $R_{r s}$ at 560 and $620 \mathrm{~nm}$. By subtracting $R_{r s}^{-1}(620)$ from $R_{r s}^{-1}(560)$, we therefore remove $a_{p c}$ from the denominator of Eq. (4), obtaining

$$
\begin{aligned}
\frac{1}{R_{r s}(620)}-\frac{1}{R_{r s}(560)} & \propto \frac{Q}{f}\left[\frac{a_{p c}(620)-a_{p c}(560)}{b_{b}(620)}+\frac{a_{w}(620)-a_{w}(560)}{b_{b}(560)}\right] \\
& \approx \frac{Q}{f} \frac{a_{w}(620)-a_{w}(560)}{b_{b}(560)}
\end{aligned}
$$

where $\frac{Q}{f} \frac{a_{w}(620)-a_{w}(560)}{b_{b}(560)}$ can be substituted by $\frac{Q}{f} \frac{a_{w}(620)-a_{w}(560)}{b_{b}(620)}$, and $a_{w}(620)-a_{w}(560)$ is equal to $0.213 \mathrm{~m}^{-1}$ according to the measurements of Pope and Fry. ${ }^{30}$ Then multiplying Eq. (7) by 0.213, we can derive a factor proportional to $b_{b}(560)$ or $b_{b}(620)$ 


$$
0.213 \times \frac{R_{r s}(560) \times R_{r s}(620)}{R_{r s}(560)-R_{r s}(620)} \propto b_{b}(560) \quad\left[\text { or } b_{b}(620)\right]
$$

Next, $R_{r s}(510)$ is used to remove $b_{b}(560)$ and $Q / f$ from Eq. (7). $R_{r s}(510)$ also satisfies Eq. (4)

$$
R_{r s}(510) \propto \frac{f}{Q} \frac{b_{b}(510)}{a_{w}(510)+a_{p c}(510)+b_{b}(510)} .
$$

Because $b_{b}(510) \ll a_{w}(510)+a_{p c}(510)$ for drinking water sources, $b_{b}(510)$ in the denominator of Eq. (9) can be neglected. Multiplying the reciprocal of Eq. (8) and the reciprocal of Eq. (9) by 0.213 , we obtain an approximation of the green-red retrieval index (GRI), as follows:

$$
\mathrm{GRI}=0.213 \times \frac{R_{r s}(560) \times R_{r s}(620)}{R_{r s}(560)-R_{r s}(620)} \times \frac{1}{R_{r s}(510)} \propto a(510) .
$$

Once the absorption coefficient at the reference band, $a(510)$, is obtained, the QAA-GRI algorithm can be developed based on the general framework of the QAA (see Sec. 3.3).

\subsubsection{Accuracy assessment}

Two indices, the root mean square error (RMSE) and the mean absolute percentage error (MAPE), were used to assess the accuracy of the QAA-GRI algorithm. The RMSE is defined as

$$
\mathrm{RMSE}=\sqrt{\frac{\sum_{i=1}^{n}\left(a_{\mathrm{retrieved}, i}-a_{\text {measured }, i}\right)^{2}}{n}},
$$

where $n$ is the number of observations, $a_{\text {measured }, i}$ and $a_{\text {retrieved, } i}$ are the measured and retrieved absorption coefficients at each station $i$, respectively. The MAPE compares the differences between the measured and retrieved absorption coefficients at all stations, and is calculated as the following:

$$
\text { MAPE }=\sum \frac{\left|a_{\text {retrieved, } i}-a_{\text {measured }, i}\right|}{a_{\text {measured }, i}} / n .
$$

\section{Results}

\subsection{Water Quality and Absorption Properties}

The descriptive statistics of water quality (including Chl- $a$ and turbidity) for all stations, as well as remote sensing reflectance and absorption coefficients of particles and CDOM at the lettered stations of Lake Qiandaohu are shown in Table 1. Variations in the concentrations of optically active constituents and absorption coefficients were found in the dataset from Lake Qiandaohu. For the whole dataset, the turbidity, which represents the TSM concentration, was small, ranging from 0.35 to 20.5 NTU, with an average of 2.27 NTU. Therefore, Lake Qiandaohu is not turbid. The concentration of Chl- $a$ ranged from 0.37 to $30.35 \mu \mathrm{g} / \mathrm{L}$, with an average value of $5.62 \mu \mathrm{g} / \mathrm{L}$, indicating that the trophic level of Lake Qiandaohu remains low.

The sums of spectral absorption coefficients of particles and CDOM, $a_{p c}(\lambda)$, matched with the corresponding remote sensing reflectance, are shown in Fig. 3(a), from which peaks at $675 \mathrm{~nm}$ can be observed due to the strong absorption of Chl- $a$. The magnitude of $a_{p c}(\lambda)$ was quite low, ranging from 0 to $\sim 1.5 \mathrm{~m}^{-1}$, with only slight variation. Therefore, Lake Qiandaohu can be characterized as relatively low-absorption water based on its optical properties. Figure 2(a) shows the average $a_{p}(\lambda), a_{p h}(\lambda)$, and $a_{\mathrm{NAP}}(\lambda)$ between 400 and $700 \mathrm{~nm}$, which indicate that the CDOM absorption generally dominated the total absorption of Lake Qiandaohu. 



Fig. 2 (a) Average absorption spectra of phytoplankton, NAP and CDOM in Lake Qiandaohu; the blue line represents the spectral absorption of pure water. (b) Ternary plots illustrating the relative contributions of phytoplankton, NAP and CDOM to absorption at different wavelengths for the dataset of Lake Qiandaohu.


Fig. 3 (a) Sum of absorption spectra of particles and CDOM $a_{p c}(\lambda)$ of Lake Qiandaohu; the thick blue line represents the absorption spectrum of pure water, $a_{w}(\lambda)$. (b) In situ remote sensing reflectance $R_{r s}(\lambda)$ of Lake Qiandaohu; the gray box marks the wavelength range from 560 to $620 \mathrm{~nm}$.

The absorption by pure water at wavelengths $>550 \mathrm{~nm}$ dominated the total absorption. As shown in Table 1, the absorption coefficient of particles at $440 \mathrm{~nm}, a_{p}(440)$, ranged from 0.045 to $0.548 \mathrm{~m}^{-1}$; the CDOM absorption coefficient at $440 \mathrm{~nm}, a_{\mathrm{CDOM}}(440)$, ranged from 0.134 to $0.435 \mathrm{~m}^{-1}$; the phytoplankton absorption coefficient at $675 \mathrm{~nm}, a_{p h}(675)$, ranged from 0.008 and $0.242 \mathrm{~m}^{-1}$, and its magnitude had a direct relationship with Chl- $a$ concentration. Figure 2(b) shows the absorption budget derived from the in situ data using a ternary plot at five different wavelengths. Spectral changes in the ternary plot reveal interesting, although expected, patterns. In the ternary plots at 440,510 , and $560 \mathrm{~nm}$, the majority of our data show that the relative contribution of CDOM dominated other constituents in Lake Qiandaohu. The relative contribution of NAP absorption never exceeded 50\% among the three constituents considered. However, the relative contribution of NAP absorption increased at $620 \mathrm{~nm}$, and the phytoplankton absorption was dominant at $675 \mathrm{~nm}$.

\subsection{Remote Sensing Reflectance}

The reflectance collected on April 6-9, 2016, was not considered because a rainstorm on April 2-3, 2016, contaminated Lake Qiandaohu with the heavy soil erosion. Therefore, the remaining 47 spectra of remote sensing reflectance are shown in Fig. 3(b). The shapes of the spectra were generally similar to many case 2 waters, although they were closer to case 1 than those from Taihu Lake [Fig. 8(b)]. ${ }^{41,42}$ The remote sensing spectrum of Lake Qiandaohu showed a low magnitude (ranging from 0 to $0.014 \mathrm{sr}^{-1}$ ), high variability in the blue and green regions, and a near-zero value in the near-infrared red (NIR) region. Furthermore, there was a weak trough around $440 \mathrm{~nm}$, which is a typical characteristic of oligotrophic waters. ${ }^{43}$ The reflectance 
showed a peak around $550 \mathrm{~nm}$, where the absorption of phytoplankton pigments was minimal, and the magnitude of reflectance in this range was mainly controlled by scattering of phytoplankton and NAP. The magnitudes of $R_{r s}(550)$ are given in Table 1, ranging from 0.003 to $0.013 \mathrm{sr}^{-1}$, with an average value of $0.006 \mathrm{sr}^{-1}$. The reflectance spectrum showed a weak trough at $665 \mathrm{~nm}$, which was caused by the Chl- $a$ absorption maximum; this magnitude was affected by the Chl- $a$ concentration and fluorescence contribution. ${ }^{44}$ The reflectance peak at $680 \mathrm{~nm}$ resulted from the minimal combined absorption of phytoplankton, NAP, and water. ${ }^{45}$ In the NIR band, the reflectance reached a minimum, approaching zero, which was caused by the increasing absorption by water and a relatively small scattering by NAP due to the low concentration of TSM. Unlike drinking waters, the reflectance in the NIR range of turbid waters would not be negligible because of the scattering that results from the high concentration of sediments. ${ }^{46}$

\subsection{QAA-GRI Calibration in Lake Qiandaohu}

In this study, the QAA-GRI is proposed specifically to retrieve $a(\lambda)$ from drinking water source, Lake Qiandaohu in this case, by establishing a relationship between $a(510)$ and the GRI. Figure 3(a) shows that the $a_{p c}(\lambda)$ spectrum measured in Lake Qiandaohu is almost flat in the 560- to 650-nm range, and Fig. 4(a) shows that the $a_{p c}(\lambda)$ variation is rather small in this range. Moreover, the absorption values in this range are much smaller than those in the blue and red bands. Figure 4(b) shows that the values of $a_{p c}(620)-a_{p c}(560)$ in Eq. (7) at all the Lake Qiandaohu stations were small, with an average far less than the value of $a_{w}(620)-a_{w}(560)$, which was $0.213 \mathrm{~m}^{-1}$. Therefore, the value of $a_{p c}(620)-a_{p c}(560)$ accounted for only a small proportion (approximately one-fifth) of the numerator of Eq. (7) and can be considered negligible, validating Eq. (7). Based on this analysis and Eq. (7), we considered the rapid decrease of $R_{r s}$ from 560 to $620 \mathrm{~nm}$, shown in Fig. 3(b), to be mainly caused by the strong absorption of pure water, rather than by particles and CDOM. These results supported the assumption used to derive the QAA-GRI: $a_{p c}(560)=a_{p c}(620)$. Hence, the QAAGRI could be cautiously calibrated based on the in situ dataset collected from Lake Qiandaohu.

Figure 5 shows the relationship between the GRI and $a(510)\left(R^{2}=0.78\right)$ using the in situ data measured from Lake Qiandaohu. Based on these data, the following equation relating the total absorption coefficients at $510 \mathrm{~nm}, a(510)$, with the GRI was obtained

$$
a(510)=0.5712 \times \mathrm{GRI}+0.081 .
$$

It should be noted that Eq. (13) overestimates $a(510)$ for oceanic waters. When the GRI approaches zero, as in oceanic cases, the $a(510)$ derived by Eq. (13) is more than two times $a_{w}(510)$, which is not supported by ocean optics. Therefore, the condition that GRI $>0.05$ is required to ensure that Eq. (13) will provide the accurate estimations for inland waters.

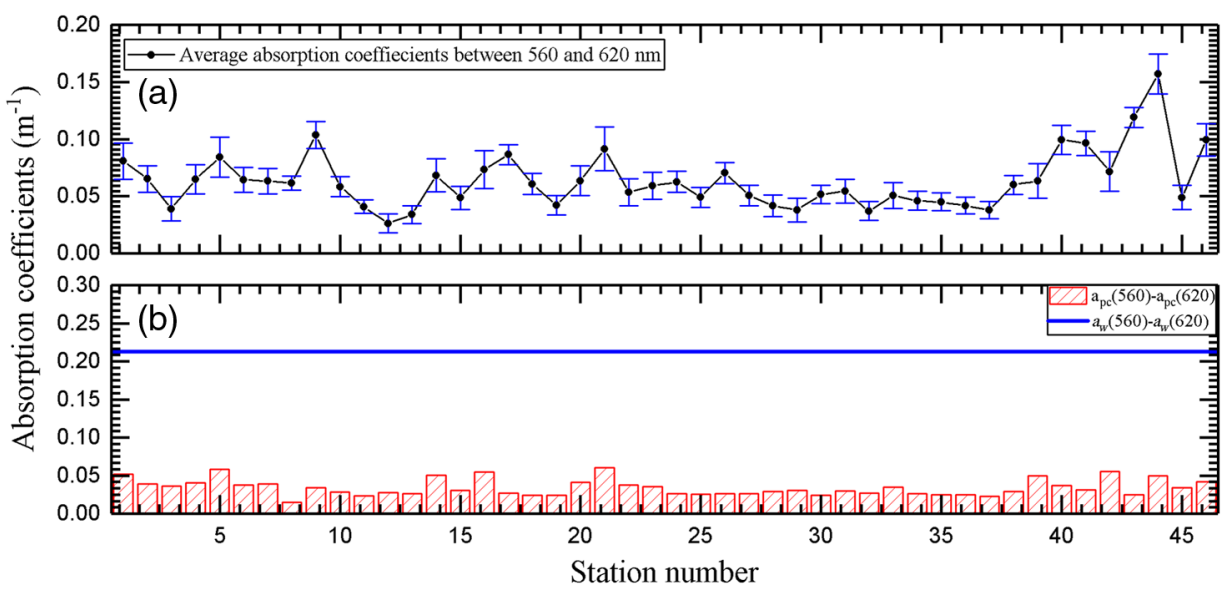

Fig. 4 (a) Average values of absorption coefficients between 560 and $620 \mathrm{~nm}$ for in situ dataset of Lake Qiandaohu. (b) Values of $a_{p c}(560)-a_{p c}(620)$ (red bar) and $a_{w}(560)-a_{w}(620)$ (blue line) for the entire dataset. 


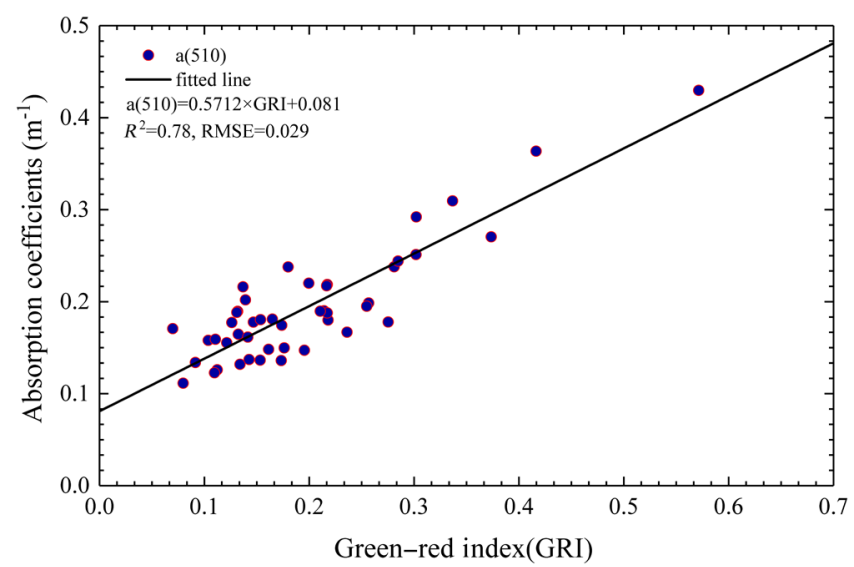

Fig. 5 Relationship between $a(510)$ and the GRI for the in situ dataset of Lake Qiandaohu.

Table 2 Steps of QAA-GRI for retrieving $a(\lambda)$. Steps $0,1,3,5$, and 6 are the same as those in QAA-v5.

\begin{tabular}{lccc}
\hline \hline Steps & Property & Derivation & Methods \\
\hline 0 & $r_{r s}$ & $=R_{r s} /\left(0.52+1.7 R_{r s}\right)$ & Semianalytical \\
1 & $u(\lambda)$ & $=\frac{-0.089+\sqrt{0.089^{2}+4 \times 0.125 r_{r s}}}{2 \times 0.125}$ & Semianalytical \\
2 & $\lambda_{0}=510 \mathrm{~nm}$ & $=0.5712 \times \mathrm{GRI}+0.081$ & Semianalytical \\
& $a\left(\lambda_{0}\right)$ & $\mathrm{GRI}=0.213 \times \frac{R_{r s}(560) \times R_{r s}(620)}{R_{r s}(560)-R_{r s}(620)} \times \frac{1}{R_{r s}(510)}$ & \\
3 & $b_{b p}\left(\lambda_{0}\right)$ & $=\frac{u\left(\lambda_{0}\right) a\left(\lambda_{0}\right)}{1-u\left(\lambda_{0}\right)}-b_{b w}\left(\lambda_{0}\right)$ & \\
4 & $Y$ & $=2.5\left\{1-1.2 \exp \left[-0.9 \frac{r_{r s}(443)}{r_{r s}\left(\lambda_{0}\right)}\right]\right\}$ & Analytical \\
5 & $a(\lambda)$ & $=b\left(\lambda_{0 b p}\right)\left(\frac{\lambda_{0}}{\lambda}\right)^{Y}$ & Empirical \\
6 & $b_{b p}(\lambda)$ & $=\frac{[1-u(\lambda)]\left[b_{b w}(\lambda)+b_{b p}(\lambda)\right]}{u(\lambda)}$ & Semianalytical \\
\hline \hline
\end{tabular}

Because the reference band used in the original QAA was shifted from 555 to $510 \mathrm{~nm}$, the coefficients of the spectral slope $(Y)$ calculation (step 4) were fine-tuned with an optimization algorithm. ${ }^{47}$ The newly developed algorithm for retrieving $a(\lambda)$, QAA-GRI, is summarized in Table 2.

\subsection{Performance of QAA-GRI Algorithm for the In Situ DataSet in Lake Qiandaohu}

This subsection presents the performance of the QAA-GRI algorithm in relation to the in situ dataset collected in Lake Qiandaohu. Figure 6 shows a scatterplot of the $a(\lambda)$ derived by the QAA-GRI and from in situ measurements at specific wavelengths. These results demonstrate that the QAA-GRI algorithm performs well in this case. Moreover, the correlation coefficients of the QAA-GRI results at 460, 490, and $510 \mathrm{~nm}$ are slightly higher than those at $560 \mathrm{~nm}$. The $\mathrm{R}^{2}$ values of the performance at $460,490,510$, and $560 \mathrm{~nm}$ are $0.66,0.77,0.78$, and 0.55 , respectively, and the MAPE values are $17.9 \%, 16.4 \%, 14.9 \%$, and $19.8 \%$, respectively. Our results are consistent with those of Lee et al., ${ }^{4}$ which indicated that the accuracy of $a(\lambda)$ retrieval around the reference band is highest, and the retrieval uncertainties tend to increase in the blue bands because of the high magnitude of $a(\lambda)$ and the complex interactions among CDOM, NAP, and phytoplankton within this range. 

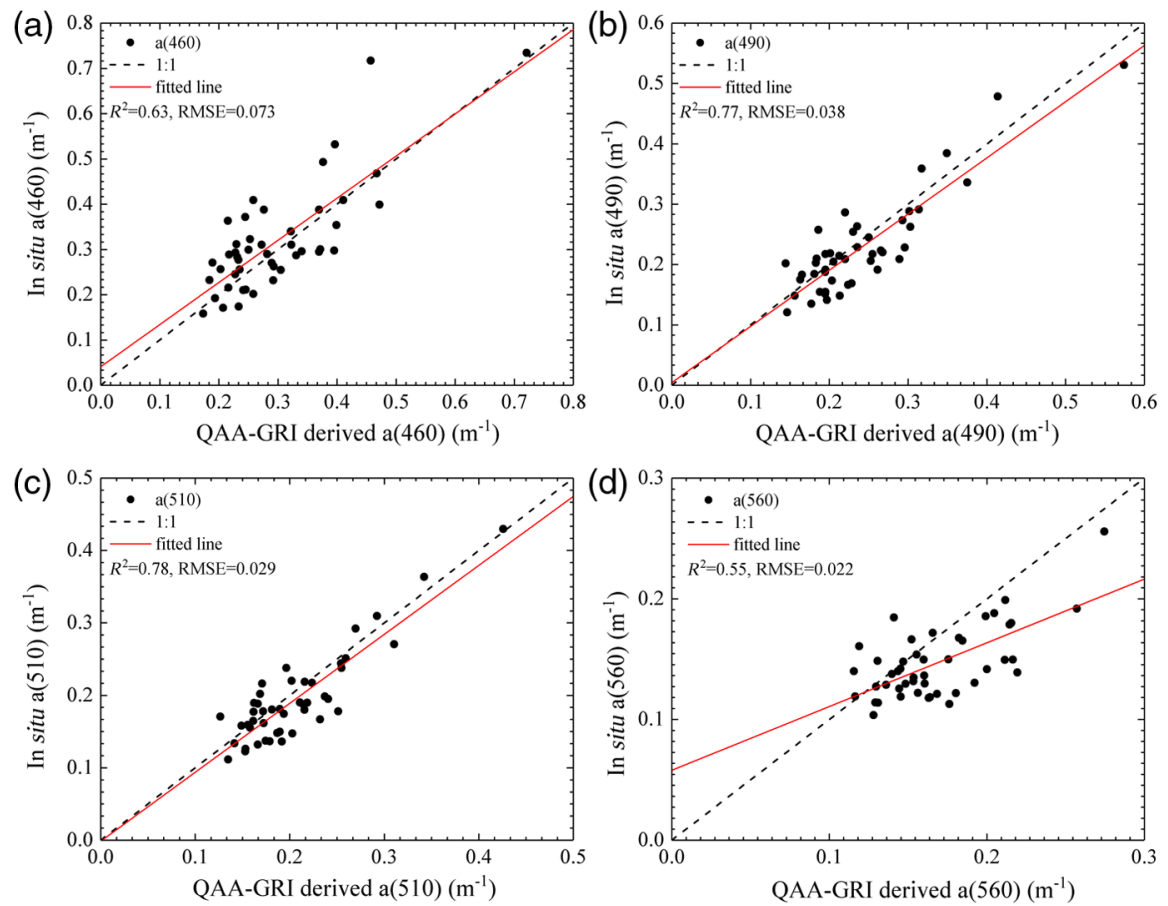

Fig. 6 Performance of the QAA-GRI algorithm on the in situ dataset of Lake Qiandaohu. (a)-(d) Relationships between the retrieved and measured $a(\lambda)$ at 460, 490, 510, and $560 \mathrm{~nm}$, respectively.

\section{Discussion}

\subsection{Comparison with Different Algorithms}

Three different algorithms for the retrieval of absorption coefficients, QAA-v5, QAA-RGR, and QAA-GRI, were applied to the same dataset from Lake Qiandaohu for comparison. Figure 7 shows scatterplots of the estimated and measured $a(\lambda)$ at different wavelengths for all three algorithms. The regression analysis clearly indicates that the newly developed QAA-GRI algorithm shows the best performance at all five wavelengths, with the highest $R^{2}$ value of 0.81 , whereas QAA-v5 and QAA-RGR yield $R^{2}$ values of 0.56 and 0.67 , respectively. The MAPE values for QAA-v5, QAA-RGR, and QAA-GRI are 21.2\%, 22.6\%, and 15.7\%, respectively. This result is attributed to the fact that the performance of QAA-v5 and QAA-RGR strongly depends on the accuracy of $a(555)$; however, these algorithms apply a simple empirical approach based on band ratio methods that can reduce some errors in $R_{r s}$ measurements but do not eliminate them. However, the band difference approach used in the QAA-GRI is less
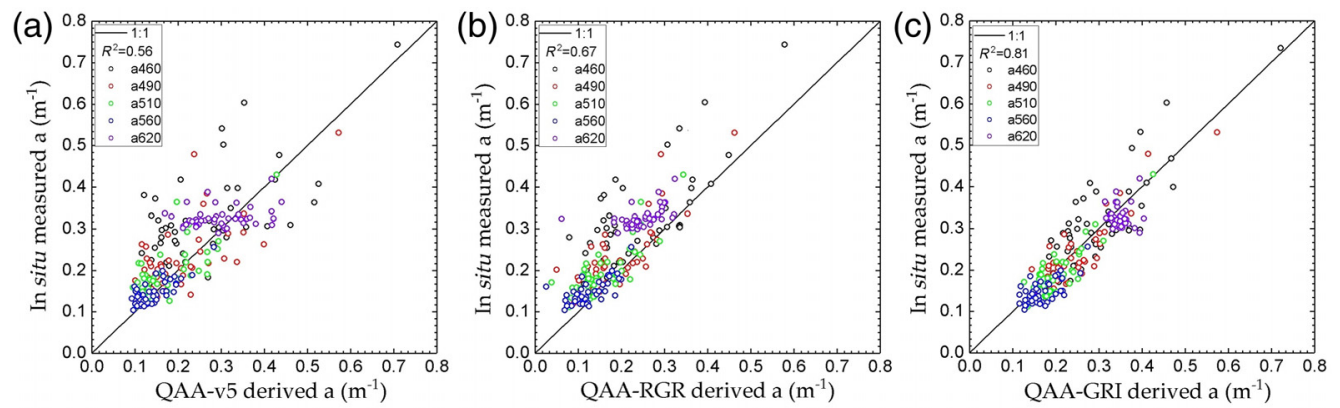

Fig. 7 Comparison of $a(\lambda)$ values estimated using (a) QAA-v5, (b) QAA-RGR, and (c) QAA-GRI in relation to the measured data from Lake Qiandaohu at 460, 490, 510, 560, and $620 \mathrm{~nm}$, respectively. 
Table 3 Comparison of QAA-v5, QAA-RGR, and QAA-GRI $a(\lambda)$ retrieval performance relative to measured data from Lake Qiandaohu at 460, 490, 510, and $560 \mathrm{~nm}$.

\begin{tabular}{lllll}
\hline \hline Absorption & Algorithm & $R^{2}$ & RMSE & MAPE (\%) \\
\hline$a(460)$ & QAA-v5 & 0.33 & 0.098 & 29.4 \\
& QAA-RGR & 0.46 & 0.087 & 27.7 \\
& QAA-GRI & 0.66 & 0.073 & 17.9 \\
$a(490)$ & QAA-v5 & 0.46 & 0.060 & 24.0 \\
& QAA-RGR & 0.63 & 0.049 & 21.0 \\
$a(510)$ & QAA-GRI & 0.77 & 0.038 & 16.4 \\
& QAA-v5 & 0.52 & 0.043 & 19.9 \\
& QAA-RGR & 0.65 & 20.8 \\
$a(560)$ & QAA-GRI & 0.78 & 0.029 & 14.9 \\
& QAA-v5 & 0.58 & 0.017 & 14.6 \\
& QAA-RGR & 0.45 & 0.021 & 19.1 \\
& QAA-GRI & 0.55 & 0.019 & 17.8 \\
& QAA-v5 & 0.07 & 0.089 & 18.6 \\
& QAA-RGR & 0.25 & 0.072 & 24.6 \\
& QAA-GRI & 0.02 & 0.038 & 9.6 \\
\hline \hline
\end{tabular}

sensitive to errors than the band ratio methods. ${ }^{48}$ The QAA-RGR has a slightly higher $R^{2}$ value compared with that of the QAA-v5; however, the former clearly underestimates $a(\lambda)$ compared with the other two algorithms. This probably is because the QAA-RGR estimates $Y$ using a "local-specific" model of $b_{b}(555)$; however, $b_{b}(555)$ is associated with more uncertainty than the band ratio of $r_{r s}$ used in QAA-v5 and QAA-GRI, and thus leads to a lower $b_{b}(\lambda)$ retrieval. Therefore, the underestimation of $a(\lambda)$ by the QAA-RGR can be regarded as due to systematic errors, and its $\mathrm{R}^{2}$ value can still be used to evaluate the algorithm performance.

The statistical parameters for the estimated and measured $a(\lambda)$ at 460, 490, 510, and $560 \mathrm{~nm}$ are given in Table 3. For the derivation of $a(620)$, the QAA-GRI yields a smaller RMSE and MAPE compared with the other two algorithms, which means that the relationship between the retrieved and measured values is closer to 1:1 line, as can also be observed from Fig. 7(c). This results occur because step 2 of the proposed model (see Table 2) results in a more accurate $a(\lambda)$ retrieval at the reference band for the in situ data of Lake Qiandaohu, which in turn significantly improves the low magnitude $a(620)$ retrieval. These results show that both QAA-v5 and QAARGR do not perform satisfactorily; however, the proposed QAA-GRI can derive more accurate estimates of absorption coefficients, particularly for waters with relatively low-absorption coefficients.

\subsection{Comparative Evaluation of Applying QAA-GRI to Taihu Lake}

Several studies have indicated that QAA-v5 and QAA-RGR cannot be applied directly to Taihu Lake. To independently evaluate the QAA-GRI in relation to the wider range of values presented by highly turbid waters, we applied the proposed algorithm to the 38 measurements of remote sensing reflectance and absorption coefficients collected in Taihu Lake. The in situ measurements of remote sensing reflectance $\left[R_{r s}(\lambda)\right]$ and absorption spectra of $a_{p c}(\lambda)$ in Taihu Lake are shown in Figs. 8(a) and 8(b), respectively. The $R_{r s}(\lambda)$ of Taihu Lake can be seen to be typical of inland eutrophic waters; its magnitude is more than three times higher than that in Lake Qiandaohu [Fig. 3(b)], and the $a_{p c}(\lambda)$ is five times higher. Furthermore, the Chl- $a$ concentration 

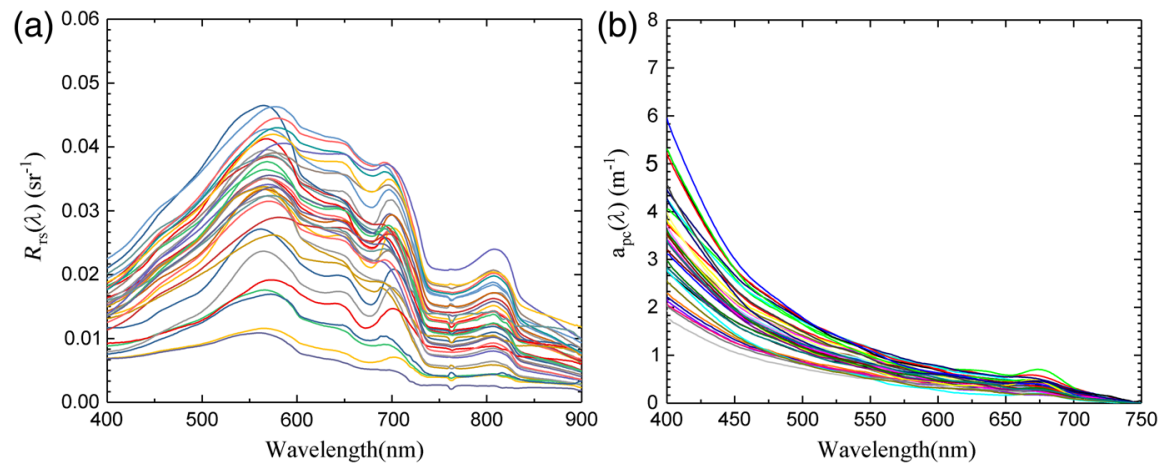

Fig. 8 (a) In situ remote sensing reflectance of Taihu Lake. (b) Sum of absorption spectra of particles and CDOM, $a_{p c}(\lambda)$, of Taihu Lake.

Table 4 Water constituent concentration in the highly turbid water from Taihu Lake.

\begin{tabular}{lccccccc}
\hline \hline & $\begin{array}{c}\text { Chl-a } \\
(\mu \mathrm{g} / \mathrm{L})\end{array}$ & $\begin{array}{c}\text { TSM } \\
(\mathrm{mg} / \mathrm{L})\end{array}$ & $\begin{array}{c}R_{r s}(550) \\
\left(\mathrm{sr}^{-1}\right)\end{array}$ & $\begin{array}{c}a_{\mathrm{P}}(440) \\
\left(\mathrm{m}^{-1}\right)\end{array}$ & $\begin{array}{c}a_{\mathrm{NAP}}(440) \\
\left(\mathrm{m}^{-1}\right)\end{array}$ & $\begin{array}{c}a_{\mathrm{CDOM}}(440) \\
\left(\mathrm{m}^{-1}\right)\end{array}$ & $\begin{array}{c}a_{p h}(675) \\
\left(\mathrm{m}^{-1}\right)\end{array}$ \\
\hline $\operatorname{Max}$ & 258.22 & 135.0 & 0.046 & 2.618 & 2.242 & 1.337 & 0.390 \\
$\operatorname{Min}$ & 3.65 & 16.8 & 0.011 & 0.188 & 0.150 & 0.537 & 0.018 \\
Avg. & 36.91 & 48.2 & 0.032 & 1.354 & 1.059 & 0.860 & 0.131 \\
Med. & 41.82 & 42.7 & 0.034 & 1.284 & 1.062 & 0.831 & 0.103 \\
Sd. & 42.55 & 23.5 & 0.009 & 0.649 & 0.561 & 0.184 & 0.092 \\
\hline \hline
\end{tabular}

and absorption coefficients vary significantly (Table 4), with larger values than those in Lake Qiandaohu (Table 1). In Taihu Lake, the Chl- $a$ concentration ranges from 3.65 to $258.22 \mu \mathrm{g} / \mathrm{L}$, with an average of $36.91 \mu \mathrm{g} / \mathrm{L}$, which indicates eutrophication. The concentration of TSM ranges from 16.8 to $135.0 \mathrm{mg} / \mathrm{L}$, with an average of $48.2 \mathrm{mg} / \mathrm{L}$, and the values of $a_{\mathrm{NAP}}(440)$ were in the range from 0.150 to $2.242 \mathrm{~m}^{-1}$, with an average of $1.059 \mathrm{~m}^{-1}$. These results provide further evidence of the high turbidity and large spatial variations in Taihu Lake.

As predicted, the performance of the QAA-GRI at five specific wavelengths in Taihu Lake $\left(R^{2}=0.45\right)$ is poorer than that in Lake Qiandaohu $\left(R^{2}=0.81\right)$. This result is attributed to the poor applicability of the QAA-GRI algorithm to Taihu Lake, which does not satisfy the assumptions used in the algorithm. The absorption coefficients of particles and CDOM in Taihu Lake were significantly higher than those in Lake Qiandaohu; therefore, the assumption applied in relation to Eq. (5) does not hold true, and the $a_{p c}(\lambda)$ difference between 560 and $620 \mathrm{~nm}$ in Taihu Lake could not be disregarded. Figure 9(b) also shows that $a_{p c}(620)-a_{p c}(560)$ had a similar magnitude for all data from Taihu Lake, or even exceeded $a_{w}(620)-a_{w}(560)$ in the numerator of Eq. (7). Furthermore, in highly turbid water with eutrophication, the assumption used in Eq. (6) may be invalid. Several studies have indicated that the backscattering coefficient in the blue and red bands may vary significantly for highly turbid waters. ${ }^{49,50}$ In addition, the magnitude of backscattering coefficients of particles in highly turbid waters is relatively larger than that in clear waters, and therefore could not to be ignored in the denominator of Eq. (7). Therefore, the two assumptions used in the QAA-GRI algorithm are not valid in highly turbid waters, and therefore the QAA-GRI could not perform as well for Taihu Lake as for Lake Qiandaohu.

\subsection{Factors Influencing QAA-GRI Application}

There are a few prerequisites for successful application of the newly developed QAA-GRI algorithm. One assumption is that $a_{p c}(560)$ equals approximately $a_{p c}(620)$, or equivalently, that 


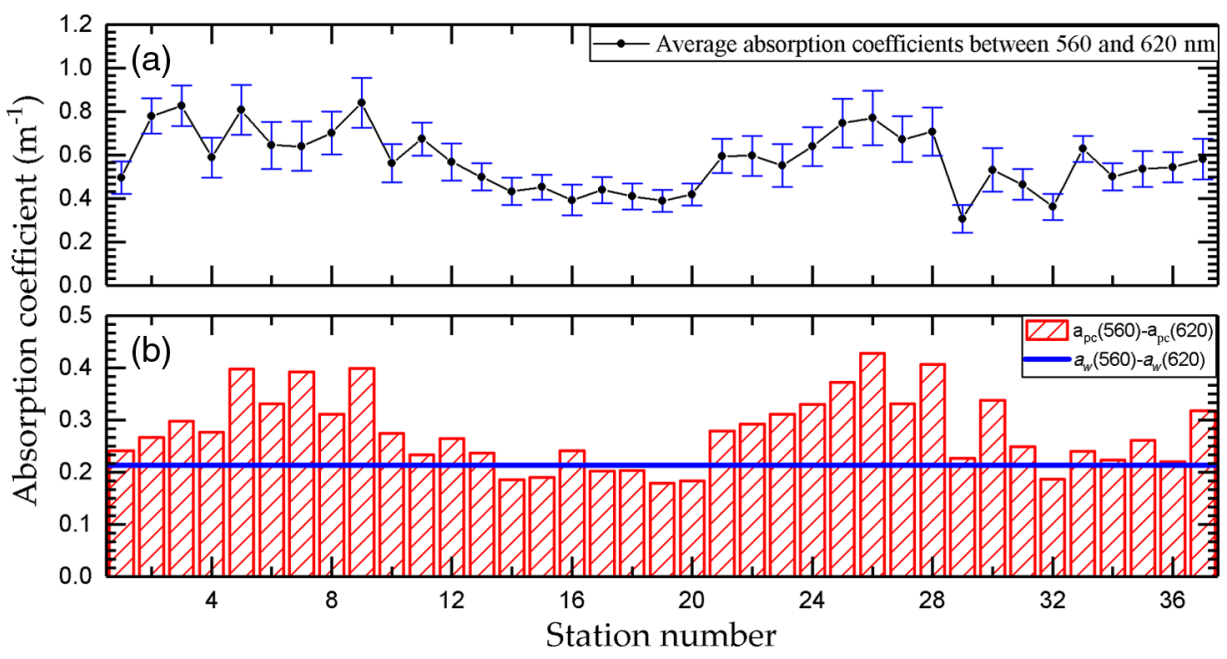

Fig. 9 (a) Average values of absorption coefficients between 560 and $620 \mathrm{~nm}$ for in situ dataset of Taihu Lake; the range of the $Y$-axis in (a) is six times that in Fig. 4(a); (b) Values of $a_{p c}(560)-$ $a_{p c}(620)$ (red bar) and $a_{w}(560)-a_{w}(620)$ (blue line) for all in situ data of Taihu Lake.

$a(560)$ equals $a(620)$ because $a(\lambda)=a_{w}(\lambda)+a_{p c}(\lambda)$ where $a_{w}(\lambda)$ is a constant. This assumption requires that the difference between $a_{p c}(560)$ and $a_{p c}(620)$ be small. Therefore, when using the QAA-GRI algorithm, one should analyze the absorption spectra of the total particulate and CDOM. The key to the successful application of the QAA-GRI is that Eq. (14) must be satisfied, particularly that "«" is fulfilled. Fortunately, this requirement for Eq. (14) is satisfied in most drinking water resources, which have low TSM concentrations

$$
a_{p c}(560)-a_{p c}(620) \ll a_{w}(620)-a_{w}(560) .
$$

For the two cases discussed above, the average value of $a_{p c}(560)-a_{p c}(620)$ for all the measurements of Lake Qiandaohu is $\sim 0.034 \mathrm{~m}^{-1}$, which is much smaller than one-sixth of the $a_{w}(620)-a_{w}(560)$ value, $0.213 \mathrm{~m}^{-1}$ [blue line in Fig. 4(b)]. However, the average magnitude of $a_{p c}(560)-a_{p c}(620)$ for the measurements of Taihu Lake is $0.279 \mathrm{~m}^{-1}$, even exceeding $0.213 \mathrm{~m}^{-1}$, as shown in Fig. 9(b). Therefore, for waters with different optical properties, if the magnitude of $a_{p c}(560)-a_{p c}(620)$ accounts for only a small proportion of Eq. (7) numerator, the value of $a_{p c}(560)-a_{p c}(620)$ could be considered negligible because its value is much smaller than $a_{w}(620)-a_{w}(560)$. In contrast, if the value of $a_{p c}(560)-a_{p c}(620)$ cannot be neglected, the assumption used in Eq. (7) would be invalid, as in the case of Taihu Lake.

Another necessary assumption used in the QAA-GRI is that the backscattering coefficients at 510,560 , and $620 \mathrm{~nm}$ have little variation; thus, $b_{b}$ was considered to be approximately the same at these wavelengths. In moderately turbid waters, such as Lake Qiandahu, $b_{b}$ is typically weak, and its magnitude is much lower than the magnitude of the total absorption coefficients. Therefore, the approximate equation, $b_{b}(510)=b_{b}(560)=b_{b}(620)$, holds true in this water body. Conversely, $b_{b}$ in Taihu Lake has a relatively large magnitude, and its values between 510 and $650 \mathrm{~nm}$ vary significantly. ${ }^{49}$ Therefore, the backscattering coefficients, $b_{b}$, can be considered neither negligible nor equal, and the QAA-GRI may generate large estimation errors when retrieving the total absorption coefficient, $a(\lambda)$, in highly turbid waters such as those of Taihu Lake.

Because these conditions must be satisfied to apply the QAA-GRI, appropriate bodies of water must be identified to apply the proposed algorithm. However, in situ IOPs are difficult to obtain for local water bodies, and the most relevant parameter that can be obtained from ocean color satellite data is remote sensing reflectance. Therefore, the following criterion is recommended for detecting waters where QAA-GRI can be successfully applied, based on a combination of the GRI and $R_{r s}$ indices: when the $R_{r s}$ peak is at $\sim 560 \mathrm{~nm}, R_{r s}(560)<0.015$, and GRI $>0.05$, the QAA-GRI can be applied to these inland waters. The $R_{r s}$ index indicates 
that the water is not highly turbid and Eq. (14) holds true; the GRI index excludes waters with optical properties similar to those of oceanic waters, and some coastal waters. ${ }^{51}$

\section{Conclusions}

A GRI based on remote sensing reflectance at three bands $(510,560$, and $620 \mathrm{~nm})$ was proposed in this study. With a semianalytical model that establishes a relationship between $a(510)$ and the GRI, the proposed QAA-GRI was developed to derive the total absorption coefficients for drinking water sources analytically. Two independent bio-optical datasets were used to evaluate the applicability and accuracy of the QAA-GRI in retrieving absorption coefficients from two different types of inland waters. Encouraging results were achieved when the algorithm was applied to Lake Qiandaohu $\left(R^{2}=0.81\right.$, MAPE $\left.=15.7 \%\right)$.

The QAA-GRI could potentially be successfully applied to oceanic waters because the assumptions upon which the QAA-GRI is based are also satisfied in these waters. If this is the case, the relationship between $a(510)$ and the GRI must be modified to accommodate the broader range of oceanic dataset. Therefore, further studies are required to extend the application of QAA-GRI, and we eagerly anticipate applying the QAA-GRI to the Ocean and Land Color (OLCI) satellite data in the near future because the three characteristic bands used in QAAGRI can be found exactly in this instrument.

\section{Acknowledgments}

This work has been supported by the National Key Research and Development Program of China (2016YFC1400901), the High-Resolution Earth Observation Systems of National Science and Technology Major Projects (41-Y20A31-9003-15/17), the Scientific Research Fund of the Second Institute of Oceanography, SOA (QNYC201602), and the Social Development Research Project of Hangzhou (20150533B06). We are grateful to Zuoming $\mathrm{Yu}$ for his critical assistance with field sample collection, and the staff of the Second Institute of Oceanography for their support in the laboratory. We also thank the anonymous reviewers for their useful comments on the article.

\section{References}

1. J. T. O. Kirk, "Light and photosynthesis in aquatic ecosystems, xvi, 509p, 2nd ed., Cambridge University Press, 1994," J. Mar. Biol. Assoc. U. K. 74(4), 987 (1994).

2. L. Gross et al., "Artificial neural networks for modeling the transfer function between marine reflectance and phytoplankton pigment concentration," J. Geophys. Res. 105(C2), 3483-3495 (2000).

3. A. Morel and S. Maritorena, "Bio-optical properties of oceanic waters: A reappraisal," J. Geophys. Res. Oceans 106(C4), 7163-7180 (2001).

4. Z. Lee, K. L. Carder, and R. A. Arnone, "Deriving inherent optical properties from water color: a multiband quasi-analytical algorithm for optically deep waters," Appl. Opt. 41(27), 5755-5772 (2002).

5. Z. Lee et al., "Penetration of UV-visible solar radiation in the global oceans: Insights from ocean color remote sensing," J. Geophys. Res. Oceans 118(9), 4241-4255 (2013).

6. C. D. Mobley, "Optical properties of water," in Light and Water: Radiative Transfer in Natural Waters, pp. 60-144, Academic Press (1994).

7. Z. P. Lee et al., "Method to derive ocean absorption coefficients from remote-sensing reflectance," Appl. Opt. 35(3), 453-462 (1996).

8. H. Loisel et al., "Spectral dependency of optical backscattering by marine particles from satellite remote sensing of the global ocean," J. Geophys. Res. Oceans 111(9) (2006).

9. J. Marra, C. C. Trees, and J. E. O'Reilly, "Phytoplankton pigment absorption: a strong predictor of primary productivity in the surface ocean," Deep. Res. Part I Oceanogr. Res. Pap. 54(2), 155-163 (2007). 
10. A. Matsuoka et al., "Seasonal variability in the light absorption properties of western Arctic waters: parameterization of the individual components of absorption for ocean color applications," J. Geophys. Res. Oceans 116(C2), 1-15 (2011).

11. E. Siswanto et al., "Empirical ocean-color algorithms to retrieve chlorophyll-a, total suspended matter, and colored dissolved organic matter absorption coefficient in the Yellow and East China Seas," J. Oceanogr. 67(5), 627-650 (2011).

12. A. M. Ciotti and A. Bricaud, "Retrievals of a size parameter for phytoplankton and spectral light absorption by colored detrital matter from water-leaving radiances at SeaWiFS channels in a continental shelf region off Brazil," Limnol. Oceanogr. Methods 4, 237-253 (2006).

13. R. Doerffer and H. Schiller, "The MERIS case 2 water algorithm," Int. J. Remote Sens. 28(3-4), 517-535 (2007).

14. G. Campbell et al., "Remote sensing of water quality in an Australian tropical freshwater impoundment using matrix inversion and MERIS images," Remote Sens. Environ. 115(9), 2402-2414 (2011).

15. C. Huang et al., "Deriving inherent optical property for highly turbid productive inland water from MERIS data by semi-analytical model: a case study in Taihu Lake, China," Aquat. Ecosyst. Health Manage. 17(3), 252-260 (2014).

16. Z. Lee et al., "An update of the quasi-analytical algorithm (QAA_v5)," (2009) http://www .ioccg.org/groups/Software_OCA/QAA_v5.pdf.

17. C. F. Le et al., "Validation of a quasi-analytical algorithm for highly turbid eutrophic water of meiliang bay in Taihu Lake, China," IEEE Trans. Geosci. Remote Sens. 47(8), 24922500 (2009).

18. W. Yang et al., "Retrieval of inherent optical properties for turbid inland waters from remotesensing reflectance," IEEE Trans. Geosci. Remote Sens. 51(6), 3761-3773 (2013).

19. S. Chen, T. Zhang, and L. Hu, "Evaluation of the NIR-SWIR atmospheric correction algorithm for MODIS-Aqua over the Eastern China Seas," Int. J. Remote Sens. 35(11-12), 4239-4251 (2014).

20. International Ocean-Colour Coordinating Group (IOCCG), "Remote sensing of inherent optical properties: fundamentals, tests of algorithms, and applications," in Reports of International Ocean-Colour Coordinating Group, Vol. 5, p. 126 (2006).

21. Z. Lee et al., "Uncertainties of optical parameters and their propagations in an analytical ocean color inversion algorithm," Appl. Opt. 49(3), 369-381 (2010).

22. L. Shi et al., "Variations in spectral absorption properties of phytoplankton, non-algal particles and chromophoric dissolved organic matter in Lake Qiandaohu," Water 9(5), 352 (2017).

23. Y. Zhang et al., "Thermal structure and response to long-term climatic changes in Lake Qiandaohu, a deep subtropical reservoir in China," Limnol. Oceanogr. 59(4), 11931202 (2014).

24. Y. Zhang et al., "Seasonal-spatial variation and remote sensing of phytoplankton absorption in Lake Taihu, a large eutrophic and shallow lake in China," J. Plankton Res. 32(7), 10231037 (2010).

25. Y. Zhang et al., "A study of absorption characteristics of chromophoric dissolved organic matter and particles in Lake Taihu, China," Hydrobiologia 592(1), 105-120 (2007).

26. E. J. Arar and G. B. Collins, Method 445.0: In Vitro Determination of Chlorophyll a and Pheophytin $a$ in Marine and Freshwater Algae by Fluorescence, pp. 1-22, United States Environmental Protection Agency (1997).

27. L. Prieur and S. Sathyendranath, "An optical classification of coastal and oceanic waters based on the specific spectral absorption curves of phytoplankton pigments, dissolved organic matter, and other particulate materials'," Limnol. Oceanogr. 26(4), 671-689 (1981).

28. C. S. Roesler, M. J. Perry, and K. L. Carder, "Modeling in-situ phytoplankton absorption from total absorption spectra in productive inland marine waters," Limnol. Oceanogr. 34(8), 1510-1523 (1989).

29. R. M. Pope and E. S. Fry, "Absorption spectrum (380-700 nm) of pure water. II. Integrating cavity measurements," Appl. Opt. 36(33), 8710 (1997).

30. M. Babin, "Variations in the light absorption coefficients of phytoplankton, nonalgal particles, and dissolved organic matter in coastal waters around Europe," J. Geophys. Res. 108(C7), 3211 (2003). 
31. B. G. Mitchell, "Algorithms for determining the absorption coefficient of aquatic particulates using the quantitative filter technique (QFT)," Proc. SPIE 1302 (1990).

32. G. S. Fargion and J. L. Mueller, Ocean Optics Protocols for Satellite Ocean Color Sensor Validation, Revision 2, NASA Goddard Space Flight Center, Greenbelt, Maryland, pp. 1-184 (2000).

33. T.-W. Cui et al., "Spectral variability of sea surface skylight reflectance and its effect on ocean color," Opt. Express 21(21), 24929-24941 (2013).

34. G. Ciraolo et al., "The classification of submerged vegetation using hyperspectral MIVIS data," Ann. Geophys. 49(1), 287-294 (2006).

35. H. R. Gordon et al., "A semianalytic radiance model of ocean color," J. Geophys. Res. 93(D9), 10909 (1988).

36. K. L. Carder and R. G. Steward, "A remote-sensing reflectance model of a red-tide dinoflagellate off west Florida," Limnol. Oceanogr. 30(2), 286-298 (1985).

37. Z. Lee et al., "Model for the interpretation of hyperspectral remote-sensing reflectance.," Appl. Opt. 33(24), 5721-5732 (1994).

38. H. Loisel and A. Morel, "Non-isotropy of the upward radiance field in typical coastal (Case 2) waters," Int. J. Remote Sens. 22(2), 275-295 (2001).

39. H. J. Gons, "Optical teledetection of chlorophyll a in turbid inland waters," Environ. Sci. Technol. 33(7), 1127-1132 (1999).

40. F. Mélin, G. Zibordi, and J. F. Berthon, "Assessment of SeaWiFS atmospheric and marine products for the Northern Adriatic Sea," IEEE Trans. Geosci. Remote Sens. 41(3), 548-558 (2003).

41. H. Duan, R. Ma, and C. Hu, "Evaluation of remote sensing algorithms for cyanobacterial pigment retrievals during spring bloom formation in several lakes of East China," Remote Sens. Environ. 126, 126-135 (2012).

42. K. Song et al., "Retrieval of total suspended matter (TSM) and chlorophyll-a (Chl-a) concentration from remote-sensing data for drinking water resources," Environ. Monit. Assess. 184(3), 1449-1470 (2012).

43. H. R. Gordon and A. Y. Morel, "Remote assessment of ocean color for interpretation of satellite visible imagery: a review," Phys. Earth Planet. Inter. 37(4), 292 (1983).

44. A. Gilerson et al., "Fluorescence component in the reflectance spectra from coastal waters. Dependence on water composition," Opt. Express 15(24), 15702 (2007).

45. A. Gitelson, "The peak near $700 \mathrm{~nm}$ on radiance spectra of algae and water: relationships of its magnitude and position with chlorophyll concentration," Int. J. Remote Sens. 13(17), 3367-3373 (1992).

46. B. Zhang et al., "A bio-optical model based method of estimating total suspended matter of Lake Taihu from near-infrared remote sensing reflectance," Environ. Monit. Assess. 145(1-3), 339-347 (2008).

47. Z. P. Lee et al., "An empirical algorithm for light absorption by ocean water based on color," J. Geophys. Res. 103(C12), 27967-27978 (1998).

48. C. Hu, Z. Lee, and B. Franz, "Chlorophyll a algorithms for oligotrophic oceans: a novel approach based on three-band reflectance difference," J. Geophys. Res. Oceans 117(C1), $1-25$ (2012).

49. R. Ma et al., "Absorption and scattering properties of water body in Taihu Lake, China: absorption," Int. J. Remote Sens. 27, 4277-4304 (2006).

50. D. Doxaran et al., "Improved correction methods for field measurements of particulate light backscattering in turbid waters," Opt. Express 24(4), 3615 (2016).

51. A. C. Teodoro and F. Veloso-Gomes, "Quantification of the total suspended matter concentration around the sea breaking zone from in-situ measurements and terra/aster data," Mar. Georesour. Geotechnol. 25(2), 67-80 (2007).

Liangliang Shi received his BS degree in geographic information system from Nanjing University of Technology in 2011, and his MS degree in geographic information system from Sichuan Normal University in 2014. Currently, he is reading for a $\mathrm{PhD}$ in marine information science and engineering from Zhejiang University. His research interests include ocean color remote sensing and remote sensing of aquatic environments. 
Bangyi Tao received his BS degree in geoscience from Zhejiang University, Hangzhou, China. He received his $\mathrm{PhD}$ in ocean color remote sensing from the Chinese Academy of Sciences. Currently, he is a deputy researcher at the State Key Laboratory of Satellite Ocean Environment Dynamics, Second Institute of Oceanography, State Oceanic Administration, China. His research interests include remote sensing of environment, ocean optics, and algae detection.

Zhihua Mao received his $\mathrm{PhD}$ in marine engineering from the Chinese Academy of Sciences. Currently, he is a professor at the State Key Laboratory of Satellite Ocean Environment Dynamic, Second Institute of Oceanography, State Oceanic Administration China. His research interests include remote sensing of environment and atmospheric correction for ocean color remote sensing.

Mingliang Liu received his MS degree from Nanjing Institute of Geography and Limnology, Chinese Academy of Sciences. Currently, he is working in Hangzhou Institute of Environmental Science, China. His research interests include water ecological environment.

Yiwei Zhang received his BS degree in marine engineering from Huazhong University of Science and Technology in 2014, China. Currently, he is reading for his $\mathrm{PhD}$ in physicoelectronics and optoelectronics from the University of Chinese Academy of Sciences. His research interests include ocean optics and ultraviolet remote sensing. 